\title{
Analgesic effect of ginger and peppermint on adolescent girls with primary dysmenorrhea
}

\author{
Sana SULTAN ${ }^{1}$, Zaheer AHMED $^{1 * ~(D), ~ A s m a ~ A F R E E N ~}{ }^{1}$, Farhat RASHID ${ }^{2}$, Fatima MAJEED ${ }^{3}$, Nauman KHALID ${ }^{4}$
}

\begin{abstract}
Present study was aimed to explore the impact of ginger and peppermint in adolescents suffering with primary dysmenorrhea. For that purpose, 150 adolescents, aged 13-22 years, with regular menstruation suffering with moderate to severe dysmenorrhea (scoring 3-5 on pain scale) and preferably not taking any medication were enrolled and randomly divided into three groups i.e. control, ginger and peppermint. Baseline data was collected with help of self-administered questionnaire. To determine comparative analgesic effect of ginger and peppermint, capsules were formulated, and each group received total number of 15 capsules in a month ( 3 capsules/day for consecutive 5 days). Compared with baseline data, ginger was found more effectual than peppermint in releasing dysmenorrhea i.e. observed scoring in case of ginger was reduced from mean value of $4.13 \pm 0.63$ to $2.10 \pm 1.52(p=0.001)$. Similarly, ginger intervention exhibited gradual betterment of $10 \%$ in symptoms of dysmenorrhea but also affected blood pressure positively $(p<0.05)$. However, blood hemoglobin and serum calcium levels acted as independent variables in ginger and peppermint groups $(p>0.05)$, not affected by any mode of intervention. It was concluded that ginger exhibited superior impact in lowering pain as compared to peppermint and control groups.
\end{abstract}

Keywords: primary dysmenorrhea; adolescent girls; ginger; peppermint; pain score; relief.

Practical Application: The investigated nutraceuticals i.e. peppermint and ginger may be effectively used exclusively or in developed food product to address the symptoms related to Primary dysmenorrhea; especially the pain in females. Moreover, ginger depicted superior impact in management of symptoms of Primary dysmenorrhea especially pain.

\section{Introduction}

Adolescence is characterized by a surge in physical, endocrinal, emotional, and mental growth, with a change from complete dependence to relative independence (Alghamdi et al., 2019; Samanta et al., 2019) Worldwide; adolescents make up to $1 / 5^{\text {th }}$ of the population and adolescents are more prone to dysmenorrhea (Madhavi \& Paruvu, 2019) Dysmenorrhea is combination of Greek words, 'dys' meaning difficult/painful, 'Meno' meaning month and 'rrhea' meaning flow. The term dysmenorrhea is meant for either primary or secondary. Primary out any pathological cause one is with and is related to physical and emotional symptoms (Yunianingrum et al., 2019). Exclusively it is experienced by the women whose ovaries can produce ovum and progesterone, where progesterone is cause for release of prostaglandins (responsible for menstrual cramps) in uterus (Barcikowska et al., 2020). Secondary type of dysmenorrhea can be the result of endometriosis, ovarian cysts, pelvic inflammation, myomas or intrauterine devices etc. (Mohamed et al., 2020). Every year, approximately 2.5 million women are reported as a victim of menstrual ailments and even in developed country like United Kingdom quality of life of 1.5 million female populations negatively affected in term of quality of life (Clayton, 2008; Cooper et al., 2019). Dysmenorrhea may lead to several economic and social and consequences. If primary dysmenorrhea is not properly treated; alone iIn the USA, 600 million working hours and 2 billion dollars are lost annually
(Chen \& Kotani, 2018; Shirooye et al., 2017). Yet in advancements of medical sciences; primary dysmenorrheal had reduced quality of life and absenteeism from school and office work (Barcikowska et al., 2020; Heshmati et al., 2016). Regardless the incidence and harshness of the disorder; the majority of women with dysmenorrhoea do not seek out therapeutic treatment or confer with health professionals (Alghamdi et al., 2019).

As dysmenorrhea, cannot be identified and confirmed by any kind of tests, so the symptoms questionnaires and scale assist in identification of the syndrome. Nearly $50 \%$ of adolescent women complaint against severe pelvic pain during first 2-3 days of their menstrual bleeding (Shahbazi et al., 2020; Yasir et al., 2014). As first-line pain defense, non-steroidal anti-inflammatory drugs (NSAIDs) are used for primary dysmenorrhea. Studies also revealed no response from the some patients to treatment with NSAIDs or oral contraceptives (Barcikowska et al., 2020; Sosorburam et al., 2019).

Although NSAIDS have significant role in management of symptoms consequence from primary dysmenorrheal; however owing to its numerous adverse effects, use of contemporary therapy is getting attention in recent time (Lee, Lee, Khalil, Lim, \& Lim, 2018; Mittal, 2019). Along with NSAIDS (Barcikowska et al., 2020) and surgical treatment (Salehi, Marzban, \& Amini, 2019) other contemporary therapy currently includes; warm compress 
(Alghamdi et al., 2019; Armour, Smith, Steel, \& Macmillan, 2019), exercise (Armour et al., 2019), vitamin K, D and E (Saei Ghare $\mathrm{Naz}$ et al., 2020), nicotinic acid (vitamin B3), thiamine (B1), magnesium and calcium (Werbach, 2004). Herbal medicines like Rosa Damascena (Lee et al., 2018) ginger (Pellow \& Nienhuis, 2018), bilberry (European blue berry, blue berry, huckleberry) (Ulbricht et al., 2009), Peppermint dried leaves (Heshmati et al., 2016) and vegan meal (Addison, 2019), chamomile, thyme, cinnamon and fennel (Shahbazi et al., 2020). Studies from Iran, China and Tehran reported the effectiveness of ginger in relieving pain (Pellow \& Nienhuis, 2018). Peppermint dried leaves have been utilized for the remedy of nausea, vomiting, morning sickness, respiratory infections, and menstrual disorders (Alghamdi et al., 2019). The purpose of the present study was to compare the ability of ginger and peppermint in relieving primary dysmenorrhea, additionally to find the relationship between dysmenorrhea and hypertension, hemoglobin and calcium levels among adolescent girls.

\section{Materials and methods}

Placebo, ginger and peppermint capsules were manufactured in the legitimate environment. Both herbs were dried under hygienic conditions in an air circulating oven in pharmaceutical laboratory and were powdered with the help of a commercial blender. Ultimately, three types of capsules placebo (250 mg Lactose as filler in capsule control), ginger root powder and peppermint capsules, $250 \mathrm{mg}$ each, were prepared by using capsule filling machine.

\subsection{Subjects}

This study was conducted according to the guidelines laid down in the Declaration of Helsinki and all procedures involving human subjects/patients were approved by BASR committee meeting of Allama Iqbal Open University (AIOU), Islamabad (Zoccatelli et al., 2018). Before collecting samples of adolescent; permission was acquired from district education officer. To collect composed participation from target population, in different schools and colleges of Rawalpindi District, Pakistan; a total of about 400 adolescents having age of 13-22 years were accessible but 150 were agreed to be a part of the study.

A participant was diagnosed with dysmenorrhea if she reported sharp pain in the abdomen either on the day, before or during the consecutive first two days of the menstrual period. Pain grading scale from $0-5$ was utilized as a tool to identify the subjects with mild to severe cramps and ache.

Girls experiencing dysmenorrhea with pain score 3-5, having regular menstruation and eager to provide informed consent were included in study. While married girls with a pre-existing diagnosed disease or herbal sensitivity and on any kind of drug treatment for primary dysmenorrhea were excluded.

\subsection{Study protocol}

From initially screened participants 150 subjects fall our criteria. Out of 150 we selected 90 subjects who were randomly divided into three groups A, B and C. Each group comprised of 30 numbers of subjects. All the subjects had been informed about the purpose, intervention and procedure of the research and reported concessions both from the subjects and their parents was attained. The study was designed based on elaborations of CONSORT items for herbal medicine interventions (Figure 1).

At base line, prevalence and impression of dysmenorrhea among participants was observed through a deliberate and self-administered questionnaire, composite of nearly 40 questions regarding age of the subject, age of menarche, flow of blood during menses, severity of pain and the associated symptoms, dysmenorrhea hindrance to academic and daily routine of life etc.

Queries about abdominal symptoms (constipation/diarrhea, vomiting, bloating), breast symptoms (Painful, tender or swollen breasts), other symptoms (dizziness, fatigue, headache, backache) and psychological symptoms (under stressed, irritable mood or bad tempered, uneasiness, anxiety and sleeplessness (insomnia) were also a part of structured questionnaire. Likewise, participants in all the groups were assessed for blood hemoglobin $(\mathrm{Hb})$ and serum calcium along with their blood pressure observations at baseline.

Each group received total number of 15 capsules in a month ( 3 capsules/day following 5 days), which they were asked to start taking 2 days prior to due date of menstrual period. Each participant reported the number of capsules they took per day and any adverse effects of capsules, if they had or any changes (either good or bad) they experienced during their menstruation. Further, during mid of each month of intervention, clinical lab tests for hemoglobin and serum calcium level were conducted and blood pressure was monitored. Likewise, pain assessment questionnaires with a 5-point scale to assess pain relief (considerably relieved, relieved, unchanged, worse, considerably worse) and related symptoms of dysmenorrhea were completed by participants.

\subsection{Statistics}

Data obtained by the questionnaire, as well as the data generated by the biochemical analysis; was subjected to statistical analysis by using SPSS 16. At baseline, volunteer's characteristics and categorical variables were expressed in frequencies and percentages and results were stated as the mean \pm the standard deviation. Biochemical test results, after applying paired $t$ test, were separately elaborated in table form for each group (placebo, ginger and peppermint) as mean, standard deviation and standard error mean along with $\mathrm{p}$-value.

\section{Results and discussion}

The existing study appears to be the first research in order to explore relative pain-relieving potential of ginger and peppermint on dysmenorrheal and their special effects on the blood parameters i.e. serum calcium, blood hemoglobin and blood pressure. Previously many studies have been conducted on health benefits of different herbs and spices in field of dysmenorrhea and related symptoms. However, this is first comparative study conducted on ginger and peppermint and control for pain management.

\subsection{Pain severity between different treatment groups}

Reported mean age of selected 90 subjects was $16.8 \pm 2.2$. Majority of the subjects (64\%) were within the range of $14-18$ years. Average age of menarche was $12.9 \pm 1.4$. However in previous study $97 \%$ participants age ranged in bracket of $19-24$ years 


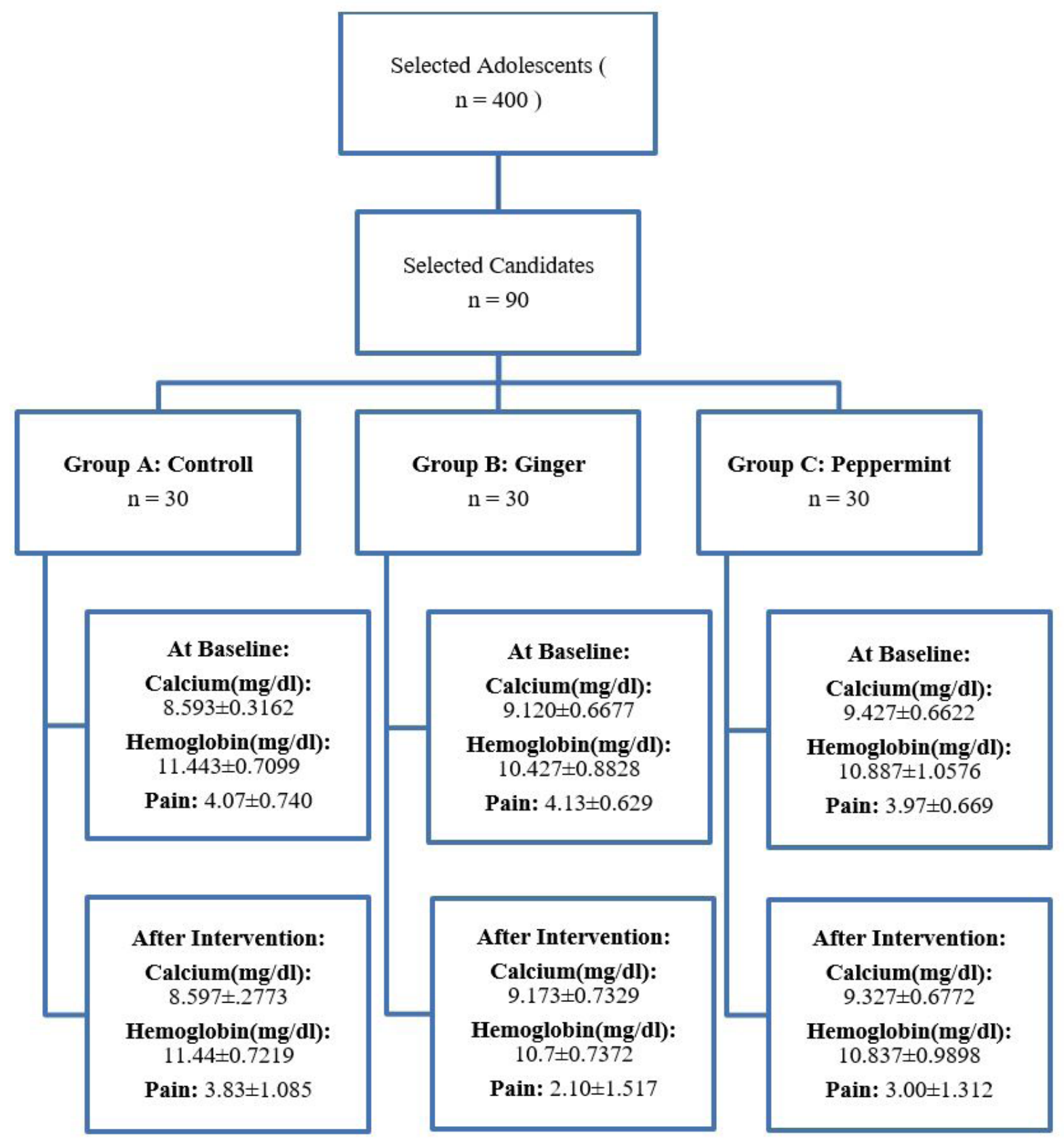

Figure 1. The flow diagram is constructed based on the elaborations of CONSORT items for herbal medicine interventions.

(Alghamdi et al., 2019) where as in another Egypt study the $72 \%$ of sample had age of greater than 17 years (Mohamed et al., 2020). Subjects presented an average duration of menses of $5.7 \pm 1.3$ days. While the recorded severity of pain in all groups (at baseline) was $4.0 \pm 0.7$. Severity of pain in different group is presented in Table 1 .

\subsection{Other characteristics/variables of study sample}

Collectively analyzed data was presented in Table 2 that shows all 90 subjects at base line $71 \%$ with normal blood low, $24 \%$ with abundant and just $4 \%$ subjects had scant flow during their menses. Twenty two percent (22\%) students were noticed with bothersome pain, $54 \%$ with intense pain $23 \%$ had been suffering from the worst unbearable pain. Our results are similar to previous study where $22 \%$ of participant experienced severe \& $60 \%$ moderate pain due to primary dysmenorrhea (Alghamdi et al., 2019). Nearly $60 \%$ of the sample subjects were found confined to the limited hour work and $28 \%$ said their menstruation forced them to stay in bed at least for half of a day. Our study also supported the statement in literature where uncomforting owing to primary dysmenorrhea had been reported as major a rationale of adolescents for absence from work or school (Barcikowska et al., 2020). As far as concerned with prevalence of dysmenorrhea, majority of the absentee cases of girls from schools in America and Taiwanese are caused by primary dysmenorrhea (Chen et al., 2006). Eighty four percent 
Table 1. Comparison of pain severity between different treatment groups.

\begin{tabular}{lcccc}
\hline \multicolumn{1}{c}{ Characteristics } & $\begin{array}{c}\text { Control Grp. } \\
(\mathrm{n}=30)\end{array}$ & Ginger Grp. & Peppermint Group $(\mathrm{n}=$ & Total \\
$(\mathrm{n}=30)$ & $17.2 \pm 2.4$ & $17 \pm 2.2$ & $16.8 \pm 2.3$ \\
Age (year) & $16.4 \pm 2.1$ & $12.6 \pm 1.3$ & $12.4 \pm 1.3$ & $12.9 \pm 1.4$ \\
Menarche age & $13.8 \pm 1.3$ & $5.56 \pm 1.6$ & $5.96 \pm 1.3$ & $5.71 \pm 1.3$ \\
Duration of menses & $5.6 \pm 1.1$ & $4.1 \pm 0.6$ & $3.9 \pm 0.7$ & $4.01 \pm 0.7$ \\
Pain scoring (before) & $3.9 \pm 0.7$ & & \\
\hline
\end{tabular}

Table 2. Characteristics/variables of study sample.

\begin{tabular}{|c|c|c|c|}
\hline Name of Variable & Category & Frequency & Percentage \\
\hline \multirow{3}{*}{$\begin{array}{l}\text { Blood flow } \\
\text { during menses }\end{array}$} & Scant & 4 & $4 \%$ \\
\hline & Normal & 64 & $71 \%$ \\
\hline & Abundant & 22 & $24 \%$ \\
\hline \multirow{3}{*}{$\begin{array}{l}\text { Pain scoring } \\
\text { intensity }\end{array}$} & Bothersome (3) & 20 & $22 \%$ \\
\hline & Intense (4) & 49 & $54 \%$ \\
\hline & Worse (5) & 21 & $23 \%$ \\
\hline \multirow{3}{*}{$\begin{array}{l}\text { Consultation } \\
\text { with doctor }\end{array}$} & Yes & 12 & $13 \%$ \\
\hline & No & 76 & $84 \%$ \\
\hline & No Response & 2 & $2 \%$ \\
\hline \multirow{3}{*}{ Self-medication } & Yes & 12 & $13 \%$ \\
\hline & No & 76 & $84 \%$ \\
\hline & No Response & 2 & $2 \%$ \\
\hline \multirow{5}{*}{ Pain description } & Sharp & 36 & $40 \%$ \\
\hline & Dull & 7 & $8 \%$ \\
\hline & Intermittent & 20 & $22 \%$ \\
\hline & Continuous aching & 16 & $18 \%$ \\
\hline & Cramping & 11 & $12 \%$ \\
\hline \multirow{5}{*}{$\begin{array}{l}\text { Duration of pain } \\
\text { During menses }\end{array}$} & Just before menses & 7 & $8 \%$ \\
\hline & Few hours before & 8 & $9 \%$ \\
\hline & 1-2 days before & 38 & $42 \%$ \\
\hline & 3-4 days before & 30 & $33 \%$ \\
\hline & Whole day & 7 & $8 \%$ \\
\hline \multirow{4}{*}{$\begin{array}{l}\text { Time of } \\
\text { dysmenorrhea }\end{array}$} & $\begin{array}{l}1 \text { day before actual } \\
\text { bleeding }\end{array}$ & 16 & $18 \%$ \\
\hline & 2 days before & 15 & $17 \%$ \\
\hline & On same day & 44 & $49 \%$ \\
\hline & $\begin{array}{l}\text { Sometimes before and } \\
\text { sometimes on same } \\
\text { day }\end{array}$ & 15 & $17 \%$ \\
\hline \multirow{6}{*}{$\begin{array}{l}\text { Hindrance in } \\
\text { daily activities }\end{array}$} & Not affected at all & 0 & 0 \\
\hline & $\begin{array}{l}\text { Limited hour work/ } \\
\text { activities or less }\end{array}$ & 36 & $40 \%$ \\
\hline & $\begin{array}{l}\text { Confined to simple } \\
\text { household }\end{array}$ & 16 & $18 \%$ \\
\hline & Stay home all day & 9 & $10 \%$ \\
\hline & Stay in bed half of day & 25 & $28 \%$ \\
\hline & Stay in bed all day & 4 & $4 \%$ \\
\hline
\end{tabular}

(84\%) of subjects didn't consult any doctor and $13 \%$ were habitual of self-medication. Majority of participants in current study reluctant to visit the physician. One reason is socioeconomic setup of Indo-Pak where majority of female population feel shyness to share gender related issues/informations with other; and even with physician. Studies have been reported where the most of female opt home remedies rather visiting the doctor (AbdElmonaem Mohamed et al., 2018)

\subsection{Impact of intervention on pain}

In control group no significant change was observed before and after intervention. While in peppermint group small change was noticed in pain intensity but an immense different was found in ginger group. The mean intensity of pain at baseline in control, ginger and peppermint group was $4.07 \pm 0.74,4.13 \pm 0.63$ and $3.97 \pm 0.67$ respectively, which at the end of intervention was turned to be $3.83 \pm 1.09,2.10 \pm 1.52$ and $3.00 \pm 1.31$ respectively (Table 3 ).

Different studies conducted in Iran and Tehran is also in favor with the findings of present study which testified the efficiency of ginger in reducing the pain of primary dysmenorrhea (Rahnama et al., 2010; Rahnama et al., 2012). In another research to explore the efficacy of ginger, Jenabi selected 70 females, who were randomly divided into two groups were on placebo and ginger capsules $(250 \mathrm{mg})$ respectively. Visual analogue scale was used to assess the treatment. Specifically, the symptoms of nausea were improved in ginger group $82 \%$, compared with placebo group showed 47\% (Jenabi, 2013; Shirooye et al., 2017).

Similarly several studies have evidenced the use of peppermint in management of symptoms related with primary dysmenorrhea (Alghamdi et al., 2019; Amoueeroknabad \& Sarafraz, 2011; Lee et al., 2018); especially different researches conducted in Iran, China reported the effectiveness of ginger in relieving pain (Pellow \& Nienhuis, 2018). Our study is supported by result reported in literature; where peppermint has been reported to lower the severity of pain but it did not show impact on duration of pain (Heshmati et al., 2016). However, in above mentioned studies the impact of pepper mint and ginger was carried on the population of different demographic areas; where diet pattern and socioeconomic patterns of subjects were different. In present study when impact of pepper mint and ginger was carried on subjects of same demographic; ginger decreased the pain more prominently as compared to peppermint and control; as depicted in Table 3. 


\subsection{Impact of intervention on blood pressure}

Likewise, ginger intervention exhibited a gradual betterment in blood pressure values i.e. baselines mean blood pressure $109 / 75 \mathrm{~mm} \mathrm{Hg}$ which turned to $112 / 77 \mathrm{~mm} \mathrm{Hg}(p<0.05)$ at end of intervention (Table 4 ). Since the peppermint and ginger both decreased the severity of pain in study subjects; which could be the reason for bit improvement in blood pressure of adolescents subjects.

Table 3. Comparison of mean severity of pain in primary dysmenorrhea before and after intervention.

\begin{tabular}{lccc}
\hline \multicolumn{1}{c}{ Group } & At baseline & $\begin{array}{c}\text { After } \\
\text { intervention }\end{array}$ & $p$-value \\
\hline Control & $4.07 \pm 0.74$ & $3.83 \pm 1.08$ & 0.293 \\
Ginger & $4.13 \pm 0.62$ & $2.10 \pm 1.51$ & 0.017 \\
Peppermint & $3.97 \pm 0.66$ & $3.00 \pm 1.31$ & 0.023 \\
\hline
\end{tabular}

Table 4. Comparison of blood pressure before and after intervention.

\begin{tabular}{lcrcc}
\hline \multicolumn{1}{c}{ Group } & Blood pressure & At baseline & $\begin{array}{c}\text { After } \\
\text { intervention }\end{array}$ & $p$-value \\
\hline \multirow{2}{*}{ Control } & BP - Systolic & $111 \pm 7$ & $112 \pm 6$ & 0.203 \\
& BP - Diastolic & $76 \pm 6$ & $76 \pm 5$ & 0.967 \\
\multirow{2}{*}{ Ginger } & BP - Systolic & $109 \pm 9$ & $112 \pm 4$ & 0.044 \\
& BP - Diastolic & $75 \pm 5$ & $77 \pm 4$ & 0.047 \\
\multirow{2}{*}{ Peppermint } & BP - Systolic & $112 \pm 9$ & $112 \pm 8$ & 0.959 \\
& BP - Diastolic & $77 \pm 5$ & $76 \pm 6$ & 0.277 \\
\hline
\end{tabular}

\section{5 impact of intervention on blood hemoglobin and calcium levels}

Results obtained from the bio-chemical tests performed on blood samples, exposed no specific and significant differences in blood hemoglobin values at baseline and after treatment in all three treatment protocols. In placebo trial blood samples showed nearly similar values of blood hemoglobin with an unnoticeable change (Figure $2 \mathrm{~A}, \mathrm{~B}, \mathrm{C}$ ).

Blood hemoglobin (HB) acted as independent variable in ginger and peppermint groups and did not affected by any intervention. Every sample in each group depicted randomly varying values of hemoglobin $(\mathrm{mg} / \mathrm{dl})$ during study time period which depicted in Figure $2 \mathrm{~A}-\mathrm{C}$. The average values of hemoglobin at base line and after intervention in all three treatment groups are mentioned in Table 5.

In the light results obtained and data analyzed it was evidenced that values of blood serum calcium depicted the same scenario as expressed by the blood hemoglobin (HB) mentioned above. Its values were least effected in all treatment protocols. Figure $2 \mathrm{~A}$ explains a graph plotted among the serum calcium values at start and then after placebo trial. Nearly the whole sample is showing same values with an unnoticeable difference. Similar trend was observed in case of peppermint and ginger group (Figure 2B, C). Serum calcium level values were either more or less the same at start and in end of research or some sample showed abrupt changes in consecutive months (Figure $2 \mathrm{D}-\mathrm{F}$ ).

For more detail average values of serum calcium at base line and after intervention in all group is explained (Table 5).

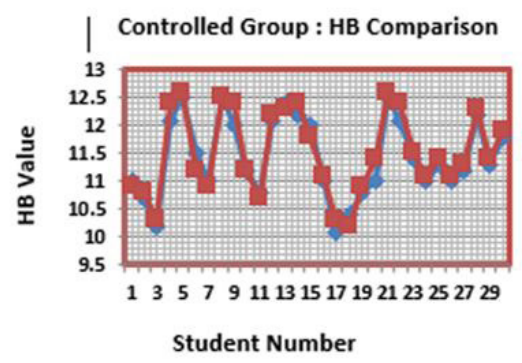

(A)

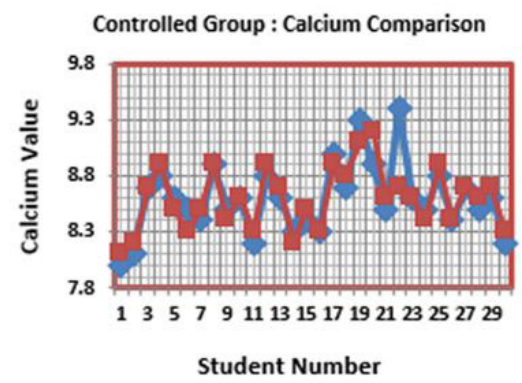

(D)

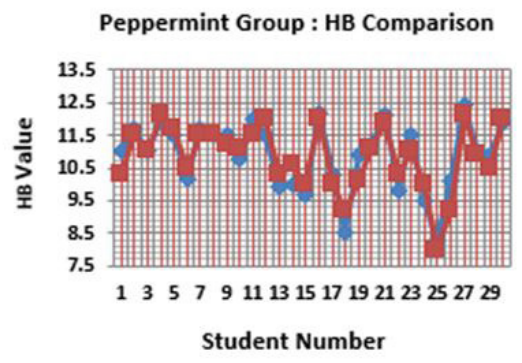

(B)

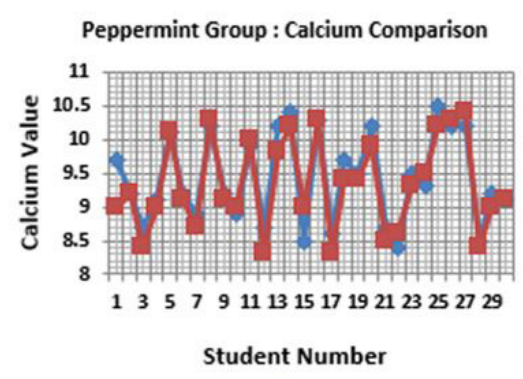

(E)

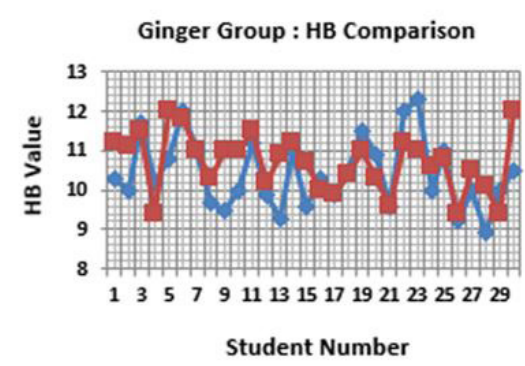

(C)

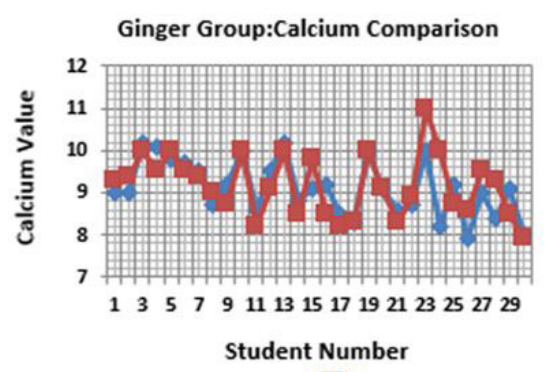

(F)

Figure 2. Column graphs showing mean variation in hematological variables of hemoglobin (A) Values of Hemoglobin at Baseline and Intervention in Placebo Group (B) Values of Hemoglobin at Baseline and Intervention in Peppermint Group (C) Values of Hemoglobin at Baseline and Intervention in Ginger Group and serum iron (D) Values of Serum Calcium at Baseline and Intervention in Placebo Group (E) Values of Serum Calcium at Baseline and Intervention in Peppermint Group (F) Values of Serum Calcium at Baseline and Intervention in Ginger Group. 
Table 5. Comparison of average value of $\mathrm{Hb}$ between three treatment groups.

\begin{tabular}{|c|c|c|c|c|c|c|}
\hline & \multicolumn{2}{|c|}{ Placebo $(\mathrm{n}=30)$} & \multicolumn{2}{|c|}{ Peppermint $(\mathrm{n}=30)$} & \multicolumn{2}{|c|}{ Ginger $(n=30)$} \\
\hline & Before & After & Before & After & Before & After \\
\hline Avg. Hb Value & $11.44 \pm 0.71$ & $11.52 \pm 0.75$ & $10.88 \pm 1.06$ & $10.84 \pm 0.99$ & $10.42 \pm 0.88$ & $10.70 \pm 0.74$ \\
\hline Avg. Calcium Value & $8.60 \pm 0.32$ & $8.61 \pm 0.28$ & $9.43 \pm 0.66$ & $9.33 \pm 0.68$ & $9.12 \pm 0.67$ & $9.17 \pm 0.73$ \\
\hline
\end{tabular}

\section{Conclusion}

Ginger is more effective in relieving menstruation pain as well as symptoms associated with primary dysmenorrhea. Here the hypothesis, "Ginger has more ability to reduce the pain, symptoms and problems of primary dysmenorrhea as compared to peppermint", proved true. Ginger maintains the blood pressure within normal range as calcium antagonistic. However the effect of ginger on blood hemoglobin and serum calcium is not so evident. Further studies about the efficacy of ginger on other symptoms associated with dysmenorrhea, inflammatory bio markers and the exact mechanism of action are justified.

\section{References}

AbdElmonaem Mohamed, E., Ahmed Attia, A., Ahmed Hassan Omran, A., \& Abd Allah ElsayedAfifi, H. (2018). Tradiational practices self reported by nursing studnets to relieve dysmenorrhea. Egyptian Journal of Health Care, 9(3), 43-59. http://dx.doi.org/10.21608/ ejhc.2018.12968.

Addison, J. (2019). Physiological changes and development during adolescence. Pediatric Board Study Guide: A Last Minute Review, 81.

Alghamdi, F., Al-Zahrani, A., \& Alabdulaziz, H. (2019). Dysmenorrhea characteristics and self-care method used among female nursing students at king abdulaziz university. Journal of Gynecology and Obstetrics, 7(1), 17-24. http://dx.doi.org/10.11648/j.jgo.20190701.13.

Amoueeroknabad, M., \& Sarafraz, N. (2011). Effect peppermint extract on primary dysmenorrhea compared with ibuprofen: a randomized clinical trial. Qom University of Medical Sciences Journal, 5(3), 37-41.

Armour, M., Smith, C. A., Steel, K. A., \& Macmillan, F. (2019). The effectiveness of self-care and lifestyle interventions in primary dysmenorrhea: a systematic review and meta-analysis. $B M C$ Complementary and Alternative Medicine, 19(1), 22. http://dx.doi. org/10.1186/s12906-019-2433-8. PMid:30654775.

Barcikowska, Z., Rajkowska-Labon, E., Grzybowska, M. E., HansdorferKorzon, R., \& Zorena, K. (2020). Inflammatory markers in dysmenorrhea and therapeutic options. International Journal of Environmental Research and Public Health, 17(4), 1191. http://dx.doi. org/10.3390/ijerph17041191. PMid:32069859.

Chen, C.-H., Lin, Y.-H., Heitkemper, M. M., \& Wu, K.-M. (2006). The self-care strategies of girls with primary dysmenorrhea: a focus group study in Taiwan. Health Care for Women International, 27(5), 418427. http://dx.doi.org/10.1080/07399330600629583. PMid:16877292.

Chen, J.-T., \& Kotani, K. (2018). Different effects of oral contraceptive and dydrogesterone treatment on oxidative stress levels in premenopausal women. Journal of Clinical Medicine Research, 10(2), 146-153. http:// dx.doi.org/10.14740/jocmr3307w. PMid:29317960.

Clayton, A. H. (2008). Symptoms related to the menstrual cycle: diagnosis, prevalence, and treatment. Journal of Psychiatric Practice, 14(1), 13-21. http://dx.doi.org/10.1097/01.pra.0000308491.54885. f8. PMid:18212599.
Cooper, K., Breeman, S., Scott, N. W., Scotland, G., Clark, J., Hawe, J., Hawthorn, R., Phillips, K., MacLennan, G., Wileman, S., McCormack, K., Hernández, R., Norrie, J., \& Bhattacharya, S., \& Health Study Group (2019). Laparoscopic supracervical hysterectomy versus endometrial ablation for women with heavy menstrual bleeding (HEALTH): a parallel-group, open-label, randomised controlled trial. Lancet, 394(10207), 1425-1436. http://dx.doi.org/10.1016/ S0140-6736(19)31790-8. PMid:31522846.

Heshmati, A., Dolatian, M., Mojab, F., shakeri, N., Nikkhah, S., \& Mahmoodi, Z. (2016). The effect of peppermint (Mentha piperita) capsules on the severity of primary dysmenorrhea. Journal of Herbal Medicine, 6(3), 137-141. http://dx.doi.org/10.1016/j.hermed.2016.05.001.

Jenabi, E. (2013). The effect of ginger for relieving of primary dysmenorrhoea. JPMA. The Journal of the Pakistan Medical Association, 63(1), 8-10. PMid:23865123.

Lee, M. S., Lee, H. W., Khalil, M., Lim, H. S., \& Lim, H.-J. (2018). Aromatherapy for managing pain in primary dysmenorrhea: a systematic review of randomized placebo-controlled trials. Journal of Clinical Medicine, 7(11), 434. http://dx.doi.org/10.3390/jcm7110434. PMid:30423839.

Madhavi, K. P., \& Paruvu, K. (2019). Menstrual hygiene and practices among adolescent girls in rural Visakhapatnam: a cross-sectional study. International Journal of Community Medicine and Public Health, 6(1), 432. http://dx.doi.org/10.18203/2394-6040.ijcmph20185284.

Mittal, R. (2019). Role of contemporary therapy in treatment of dysmenorrhea. International Journal of Advance Research. Ideas and Innovations in Technology, 5(1), 9-11.

Mohamed, E. A. E., Ahmed Attia, A., Hassan Omran, A. A., \& Elsayed Afifi, H. A. A. (2020). Traditional practices self reported by nursing students to relieve dysmenorrhea. Egyptian Journal of Health Care, 11(1), 176-190. http://dx.doi.org/10.21608/ejhc.2020.74777.

Pellow, J., \& Nienhuis, C. (2018). Medicinal plants for primary dysmenorrhoea: a systematic review. Complementary Therapies in Medicine, 37, 13-26. http://dx.doi.org/10.1016/j.ctim.2018.01.001. PMid:29609924.

Rahnama, P., Fallah Huseini, H., Mohammadi, H., Modares, M., Khajavi Shojaee, K., Askari, M., \& Mozayani, P. (2010). The effects of zingiber officinal R. on primary dysmenorrhea. Faslnamah-i Giyahan-i Daruyi, 4(36), 81-86.

Rahnama, P., Montazeri, A., Huseini, H. F., Kianbakht, S., \& Naseri, M. (2012). Effect of Zingiber officinale R. rhizomes (ginger) on pain relief in primary dysmenorrhea: a placebo randomized trial. $B M C$ Complementary and Alternative Medicine, 12(1), 92. http://dx.doi. org/10.1186/1472-6882-12-92. PMid:22781186.

Saei Ghare Naz, M., Kiani, Z., Rashidi Fakari, F., Ghasemi, V., Abed, M., \& Ozgoli, G. (2020). The effect of micronutrients on pain management of primary dysmenorrhea: a systematic review and meta-analysis. Journal of Caring Sciences, 9(1), 47-56. http://dx.doi. org/10.34172/jcs.2020.008. PMid:32296659.

Salehi, A., Marzban, M., \& Amini, F. (2019). Effect of foeniculum vulgare on primary dysmenorrhea: a systematic review and meta-analysis. Women's Health Bulletin, 6(1), In press. http://dx.doi.org/10.5812/ whb.74240. 
Samanta, A., Thakur, J., \& Goswami, M. (2019). Menstrual characteristics and its association with socio-demographic factors and nutritional status: a study among the urban slum adolescent girls of West Bengal, India. Anthropological Review, 82(2), 105-124. http://dx.doi. org/10.2478/anre-2019-0008.

Shahbazi, F., Eslampanah, Z., \& Niaparast, M. (2020). Prevalence of symptoms and medication use among female medical students and pharmacy clients with premenstrual syndrome: a cross-sectional study in Iran. Journal of Pharmacy Practice and Research, 50(1), 55-60. http://dx.doi.org/10.1002/jppr.1609.

Shirooye, P., Hashem-Dabaghian, F., Hamzeloo-Moghadam, M., Afrakhteh, M., Bioos, S., \& Mokaberinejad, R. (2017). A clinical comparative study of oral and topical ginger on severity and duration of primary dysmenorrhea. Research Journal of Pharmacognosy, 4(1), 23-32.

Sosorburam, D., Wu, Z., Zhang, S., Hu, P., Zhang, H.-y., Jiang, T., Ahiasi-Mensah, J., \& He, X. (2019). Therapeutic effects of traditional Chinese herbal prescriptions for primary dysmenorrhea. Chinese Herbal Medicines, 11(1), 10-19. http://dx.doi.org/10.1016/j. chmed.2018.11.001.
Ulbricht, C., Basch, E., Basch, S., Bent, S., Boon, H., Burke, D., Costa, D., Falkson, C., Giese, N., Goble, M., Hashmi, S., Mukarjee, S., Papaliodis, G., Seamon, E., Tanguay-Colucci, S., Weissner, W., \& Woods, J. (2009). An evidence-based systematic review of bilberry (Vaccinium myrtillus) by the natural standard research collaboration. Journal of Dietary Supplements, 6(2), 162-200. http:// dx.doi.org/10.1080/19390210902861858. PMid:22435415.

Werbach, M. R. (2004). Nutrients in the treatment of dysmenorrhea. Townsend Letter for Doctors and Patients, 256, 128-130.

Yasir, S., Kant, B., \& Dar, M. F. (2014). Frequency of dysmenorrhoea, its impact and management strategies adopted by medical students. Journal of Ayub Medical College, Abbottabad, 26(3), 349-352. PMid:25671945.

Yunianingrum, E., Widyastuti, Y., \& Margono, M. (2019). The effect of warm compress and aromatherapy lavender to decreasing pain on primary dysmenorrhea. Jurnal Kesehatan Ibu dan Anak, 12(1), 39-47.

Zoccatelli, D., Tramèr, M. R., \& Elia, N. (2018). Identification of ethics committees based on authors' disclosures: cross-sectional study of articles published in the European Journal of Anaesthesiology and a survey of ethics committees. BMC Medical Ethics, 19(1), 57. http:// dx.doi.org/10.1186/s12910-018-0289-y. PMid:29884170. 